\title{
Editorial
}

\section{Anxiety, Depression, and its Relationship with Migraine}

The pathophysiology of migraine has intrigued the headache specialists for nearly one century. ${ }^{[1]}$ Over the last few decades, the emphasis is not only to explain the genesis of aura, pain, typical throbbing character, unilaterality of pain, and the reason for the complications of migraine but also to understand and to predict the transformation of episodic migraine to chronic migraine and thereby also to understand the relationship of migraine to tension-type headache. ${ }^{[2]}$ One aspect of migraine that is related to chronification of pain is the study of the various psychiatric comorbidities that include the anxiety, depression, somatization, and pain catastrophizing. Migraine itself is a polygenetic disorder; however, it has an influence of environmental factors that may determine the frequency, duration, and chronification of pain. The predisposition to psychiatric comorbidities may play a role. There are many studies that have found a relationship between migraine and anxiety/depression..$^{[3-5]}$ However, the phenomenon of somatization and pain catastrophization has largely remained less well studied in the area of headaches. ${ }^{[6]}$ This is not unusual to see patients with chronic migraine also suffering from other pain and non-pain symptoms at different time points, thereby suggesting an existence of a relationship of migraine and somatic symptom disorder. Pain catastrophizing is another aspect of chronic pain that is not adequately studied. Pain catastrophizing is the amplification of pain by negative thoughts that work through (a) exaggerated concern about negative consequences of pain or "magnification", (b) repetitive thoughts about pain or "rumination", (c) and a belief that nothing is going to change the pain or "helplessness." [6] This is considered as one of the pathways of formation/ consolidation of chronic pain circuits in the brain. Pain catastrophizing may also have role in making these chronic pains refractory to the treatment.

However, it is not easy to determine the "cause and effect" relationship of migraine with the psychiatric comorbidities. The first step is to study the prevalence of these psychiatric comorbidities in migraine patients and to compare it with normal controls in the same population. If we could demonstrate a higher prevalence of anxiety and depression in migraine patients as compared to normal population, the next step is to understand the relationship of migraine to these psychiatric comorbidities. Are these psychiatric comorbidities unique to migraine? Are they also seen in other chronic/episodic pain syndromes? Therefore, it is important to compare the prevalence of these psychiatric comorbidities with non-headache pain controls before we could draw any meaningful correlation of these psychiatric comorbidities with migraine. A long-term longitudinal prospective study of migraine patients with and without these comorbidities will be of great help to understand the natural history of migraine in the presence and absence of these psychiatric comorbidities. Our understanding of an acute and chronic migraine has enhanced due to such studies in the past. ${ }^{[7]}$ Finally, the third step is to understand how a therapeutic intervention to treat these psychiatric conditions affects the disability related to migraine? The study by Ram Mohan et al. is a meaningful first step in understanding the prevalence of migraine in a specific geographical location. ${ }^{[8]}$ It is of utmost importance to take it further and study how these psychiatric comorbidities affect the migraine phenotype. The authors did not compare the prevalence of anxiety and depression in their normal controls. They could have used historical controls from the prevalence studies on anxiety and depression in normal individuals done in their geographical areas. This assumes importance in view of the low prevalence of anxiety and depression in their study. However, in view of dearth of such studies, the present study is an important contribution in the understanding of migraine and its relationship with the psychiatric comorbidities.

Vimal Kumar Paliwal

Department of Neurology, Sanjay Gandhi Postgraduate Institute of Medical Sciences, Lucknow, Uttar Pradesh, India

Address for correspondence: Dr. Vimal Kumar Paliwal, Department of Neurology, Sanjay Gandhi Postgraduate Institute of Medical Sciences, Raebareli Road, Lucknow - 226014 , Uttar Pradesh, India. E-mail: dr_vimalkpaliwal@rediffmail.com

\section{REFERENCES}

1. Leão AA. Spreading depression of activity in the cerebral cortex. J Neurophysiol 1944;7:359-90.

2. Smitherman TA, Maizels M, Penzien DB. Headache chronification: Screening and behavioral management of comorbid depressive and anxiety disorders. Headache 2008;48:45-50.

3. Baskin SM, Lipchik GL, Smitherman TA. Mood and anxiety disorders in chronic headache. Headache 2006;46 Suppl 3:S76-87.

4. Antonaci F, Nappi G, Galli F, Manzoni GC, Calabresi P, Costa A, et al. Migraine and psychiatric comorbidity: A review of clinical findings. J Headache Pain 2011;12:115-25.

5. Breslau N. Psychiatric comorbidity in migraine. Cephalalgia 1998;18 Suppl 22:56-8.

6. Uniyal R, Paliwal VK, Tripathi A. Psychiatric comorbidity in new daily persistent headache: A cross-sectional study. Eur J Pain 2017;21:1031-8.

7. Bigal ME, Lipton RB. When migraine progresses: Transformed 
or chronic migraine. Expert Rev Neurother 2006;6:297-306.

8. Rammohan K, Mundayadan SM, Das S, Shaji CV. Migraine and mood disorders: prevalence, clinical correlations and disability. J Neurosci Rural Pract 2018;10:28-33.

This is an open access journal, and articles are distributed under the terms of the Creative Commons Attribution-NonCommercial-ShareAlike 4.0 License, which allows others to remix, tweak, and build upon the work non-commercially, as long as appropriate credit is given and the new creations are licensed under the identical terms.

\begin{tabular}{|l|l|}
\hline \multicolumn{2}{c|}{ Access this article online } \\
\hline Quick Response Code: & Website: \\
\hline
\end{tabular}

How to cite this article: Paliwal VK. Anxiety, depression, and its relationship with migraine. J Neurosci Rural Pract 2019;10:4-5. 